JPDN ISSN 2579-6461 (Online) ISSN 2460-6324 (Print)

Jurnal Pendidikan Dasar Nusantara

Volume 6| Nomor 1 | Juli 2020|

DOI: https://doi.org/10.29407/jpdn.v6i1.14559

\title{
META ANALISIS: PENDEKATAN SAINTIFIK TERHADAP HASIL BELAJAR SISWA
}

\author{
Kharisma Eka Putri \\ kharismaputri@unpkediri.ac.id \\ PGSD, FKIP, UN PGRI Kediri ${ }^{1}$ \\ No Handphone: +6285736226804
}

\begin{abstract}
Abstrak: Tujuan dari penelitian ini adalah untuk menganalisis pengaruh pendekatan saintifik terhadap hasil belajar siswa pada subjek kelas, tema, dan media pembelajaran di Sekolah Dasar. Dalam penelitian ini menggunakan metode penelitian meta-analisis dengan 10 artikel sebagai sampel dari jurnal nasional dan instrumennya adalah lembar dengan pengkodean (coding category). Penelitian meta-analisis menunjukkan bahwa pada subjek kelas, pendekatan saintifik berpengaruh tinggi terhadap hasil belajar siswa pada subjek kelas rendah. Pada subjek tema pembelajaran, pendekatan saintifik berpengaruh tinggi terhadap hasil belajar siswa pada pembelajaran non tema. Sedangkan dari subjek media pembelajaran yang digunakan, pendekatan saintifik berpengaruh tinggi terhadap hasil belajar siswa pada media papan berpaku.
\end{abstract}

Kata kunci: meta-analisis, pendekatan saintifik, hasil belajar siswa

\section{JUDUL BAHASA INGGRIS}

\begin{abstract}
The purpose of this study is to analyze the effect of the scientific approach on the student learning result of Class Subjects, Themes, and Learning Media in elementary schools. In this study using a meta-analysis research method with 10 articles samples from national journals and the instrument is a coding category. The meta-analysis research shows that on the subject class, the scientific approach has a high effect on the student learning result on low grade subjects. For the subject of learning themes, the scientific approach has a high effect on the student learning result in non-theme learning. While from the subject of instructional media, the scientific approach has a high effect on the student learning result in the "papan berpaku" media.
\end{abstract}

Keywords: meta-analysis, the scientific approach, the student learning result 
Kharisma. Meta Analisis : Pendekatan Saintifik

PENDAHULUAN

Jenjang pendidikan Sekolah Dasar, pada kurikulum 2013 yang menggunakan pendekatan tematik integrative pada kegiatan pembelajarannya. Berdasarkan permendikbud RI Nomor 57 Tahun 2014 pasal 11 ayat 1 telah disebutkan bahwa pelaksanaan pembelajaran pada Sekolah Dasar atau Madrasah Ibtidaiyah dilakukan dengan pendekatan pembelajaran tematik-terpadu atau tematik integrative. Pembelajaran tematik integratif arti yang lainnya adalah sebuah kegiatan pembelajaran yang tidak terpisah dan menghubungkan berbagai kemampuan atau kompetensi dan mata pelajaran dalam berbagai tema. (Fogarty, 2009: 92) menyatakan:

The The integrated curricular model represents a cross disciplinary approach similar to the shared model. The integrated model blends the four major disciplines by setting curricular priorities in each and finding the overlapping skills, concept, and attitude in all four.

Pernyataan di atas dapat diartikan bahwa model pembelajaran terintegrasi yang disusun dengan menggabungkan berbagai disiplin ilmu dengan menentukan ketrampilan, konsep, dan sikap yang saling tumpang tindih.

Pembelajaran tematik merupakan karakteristik utama dalam kurikulum 2013 Sekolah Dasar, karena pengemasan dalam kurikulum 2013 dalam bentuk tema yang terdiri dari beberapa mata peajaran yang terintegrasi. Selain menggunakan pembelajaran tematik, karaktristik utama dalam kurikulum 2013 trutama di Sekolah Dasar adalah dengan menggunakan pendekatan saintifik. Hal ini sesuai dengan Permendikbud No. 65 Tahun 2013 menyatakan pendekatan saintifik atau pendekatan ilmiah merupakan pendekatan dalam kurikulum 2013.

Sedangkan menurut (Sudarwan, 2013) pendekatan saintifik ditujukan untuk memberi pemahaman kepada siswa agar mengetahui, memahami, mempraktikan yang dipelajari secara ilmiah. Jadi, dalam proses pembelajaran siswa diajarkan agar siswa mencari tahu dari berbagai literature melalui langkah mengamati, menanya, mencoba, mengolah, menyajikan, menyimpulkan, dan mencipta untuk keseluruhan mata pelajaran. Melalui pendekatan saintifik, peserta didik belajar berdasarkan langkah-langkah metode ilmiah tersebut, sehingga melalui penelitian ini, dapat diketahui pengaruh pendekatan saintifik terhadap hasil belajar. 
Kharisma. Meta Analisis : Pendekatan Saintifik

Untuk mewujudkan pembelajaran yang menggunakan pendekatan sintifik perlu dikombinasikaan dengan media pembelajaran yang tepat dan sesuai dengan tema pembelajaran. Sumber lain menyatakan bahwa dalam memilih media hendaknya memperhatikan kriteria-kriteria sebagai berikut:

a. Kemampuan mengakomodasikan penyajian stimulus yang tepat (visual dan/ atau audio)

b. Kemampuan mengakomodasikan respon siswa yang tepat (tertulis, audio, dan/ atau kegiatan fisik)

c. Kemampuan mengakomodasikan umpan balik

d. Pemilihan media utama dan media sekunder untuk penyajian informasi atau stimulus, dan untuk latihan dan tes (sebaiknya latihan dan tes menggunakan media yang sama)

e. Tingkat kesenangan (preferensi lembaga, guru, dan pelajar) dan keefektivan biaya (Azhar Arsyad, 2011:71)

Berdasarkan uraian di atas, maka peneliti bertujuan melakukan analisis keefektifan pembelajaran yang menggunakan pendekatan saintifik terhadap hasil belajar siswa yang ditinjau dari kelas rendah dan kelas tinggi Skolah Dasar, tema pembelajaran, dan media yang digunakan. Seperti umumnya penelitian meta-analisis ini diharapkan dapat bermanfaat dalam bidang pendidikan khususnya pengajar sekolah dasar dapat memilih tema pembelajaran, dan media yang digunakan.

\section{METODE}

Metode yang digunakan dalam penelitian ini adalah metode meta-analisis dengan mengkaji 10 artikel di jurnal nasional. Meta-analisis bersifat kuatitatif hal ini karena menggunakan hitungan angka dan statistik untuk mencari kepraktisan, yaitu menyusun dan mengekstraksi informasi dari data yang banyak, yang tidak mungkin dilakukan dengan metode yang lain (Glass, 1981).

Penelitian meta-analisis di sini menggunakan sampel 10 artikel jurnal nasional mengenai pendekatan saintifik terhadap hasil belajar siswa. Perolehan 10 artikel subjek penelitian dapat dilihat pada table di berikut ini: 
Kharisma. Meta Analisis : Pendekatan Saintifik

Tabel 1. Pemetaan Pemerolehan Artikel

Sumber: Dokumen Peneliti

\begin{tabular}{|l|c|c|c|}
\hline \multicolumn{1}{|c|}{ Keterangan } & SD Kelas & Tema Pembelajaran & Media \\
\hline SD Kelas Rendah & 2 & & \\
\hline SD Kelas Tinggi & 8 & & \\
\hline Indahnya Negriku & & 1 & \\
\hline Ekosistem & & 1 & \\
\hline Peristiwa dalam Kehidupan & & 1 & \\
\hline Makanan Sehat & & 1 & \\
\hline Sehat itu Penting & & 3 & 3 \\
\hline Tema tidak disebutkan & & & 2 \\
\hline Non Tema & & & 1 \\
\hline Adobe Flash & & & 2 \\
\hline Audio Visual & & & \\
\hline Gambar & & & \\
\hline Papan Berpaku & & & \\
\hline Genius Turtle Card & & & \\
\hline Non Media & & & \\
\hline
\end{tabular}

Coding atau pengkodingan di dalam meta-analisis adalah syarat utama agar dapat mempermudah pengumpulan dan menganalisis data. Jadi instrument dalam meta-analisis ini dilakukan dengan lembar pemberian kode. Oleh karena itu, variable yang dipakai dalam membarikan kode sehingga dapat menghasilkan informasi yang diperlukan dalam menghitung besarnya pengaruh pendekatan pendekatan saintifik pada pembelajaran tematik adalah nama peneliti dan tahun penelitian, judul penelitian, jenjang atau tingkat kelas subjek penelitian, tema yang digunakan dalam penelitian, dan jenis media yang dipergunakan, serta variable terikat penelitian.

Langkah atau prosedur tabulasi data adalah sebagai berikut (1) mengidentifikasi variabel yang ada dalam penelitian. Yang setelah ditemukan, dimasukkan dalam kolom variabel yang sesuai, (2) mengidentifikasi rata-rata dan deviasi standar dari data kelompok eksperimen maupun kelompok kontrol untuk setiap subjek atau subpenelitian, (3) penghitungan besar effect size dengan menggunakan rumus (Glass, 1981) berdasarkan rata rata dan deviasi standar yang sudah dilakukan, yaitu dengan mencari besarnya effect size dengan jalan membagi selisih rata-rata kelompok eksperimen $(X \mathrm{E})$ dengan rata-rata kelompok kontrol $(X \mathrm{~K})$, dengan deviasi standar kelompok kontrol (SK). Rumusnya adalah

$$
\text { effect size }=\frac{\text { ratarata kelompok eksperimen }(X \mathrm{E})-\text { ratarata kelompok kontrol }(X \mathrm{~K})}{S D \text { kontrol }}
$$


Kharisma. Meta Analisis : Pendekatan Saintifik

Dengan kriteria ukuran effek sebagai berikut:

effect size $\leq$ 0,15 efek yang dapat diabaikan

$0,15<$ effect size $\leq 0,40$ efek kecil

$0,40<$ effect size $\leq 0,75$ efek sedang

$0,75<$ effect size $\leq 1,10$ efek tinggi

$1,10<$ effect size $\leq 1,45$ efek yang sangat tinggi

$1,45<$ effect size pengaruh yang tinggi

\section{HASIL}

Berdasarkan kajian terhadap 10 artikel penelitian mengenai pendekatan sintifik terhadap hasil belajar siswa diperoleh table tabulasi sebagai berikut :

\section{Tabel 2. Tabel Tabulasi 10 artikel Pendekatan Saintifik terhadap Hasil Belajar Siswa \\ Sumber: Dokumen Peneliti}

\begin{tabular}{|c|c|c|c|c|c|c|c|c|c|}
\hline $\begin{array}{c}\text { Kode } \\
\text { Artikel }\end{array}$ & $\begin{array}{c}\text { Penulis, } \\
\text { Tahun }\end{array}$ & Tema & Media & $\begin{array}{l}\text { Kel } \\
\text { as }\end{array}$ & $\begin{array}{c}\text { Rata- } \\
\text { rata } \\
\text { Eks }\end{array}$ & $\begin{array}{l}\text { Rata- } \\
\text { rata } \\
\text { Kont } \\
\text { r }\end{array}$ & SD & $\begin{array}{l}\text { Effec } \\
t \text { size }\end{array}$ & Kategori \\
\hline AR-01 & $\begin{array}{l}\text { Pangestika, } \\
2018\end{array}$ & $\begin{array}{l}\text { Indahnya } \\
\text { Negriku }\end{array}$ & $\begin{array}{l}\text { Adobe } \\
\text { Flash }\end{array}$ & IV & 85,33 & 78,67 & 4,88 & 1,36 & $\begin{array}{l}\text { Efek yang } \\
\text { sangat } \\
\text { tinggi }\end{array}$ \\
\hline AR-02 & $\begin{array}{l}\text { Ernawati, } \\
2015\end{array}$ & Ekosistem & $\begin{array}{l}\text { Audio } \\
\text { Visual }\end{array}$ & V & 83,44 & 64,25 & 11,21 & 1,71 & $\begin{array}{l}\text { Pengaruh } \\
\text { yang tinggi }\end{array}$ \\
\hline AR-03 & $\begin{array}{l}\text { Rahmawati, } \\
2019\end{array}$ & $\begin{array}{l}\text { Peristiwa } \\
\text { dalam } \\
\text { Kehidupan }\end{array}$ & $\begin{array}{l}\text { Non } \\
\text { Media }\end{array}$ & $\mathrm{V}$ & 80,65 & 66,72 & 10,96 & 1,27 & $\begin{array}{l}\text { Efek yang } \\
\text { sangat } \\
\text { tinggi }\end{array}$ \\
\hline AR-04 & $\begin{array}{l}\text { Maulida, } \\
2020\end{array}$ & $\begin{array}{l}\text { Makanan } \\
\text { Sehat }\end{array}$ & $\begin{array}{l}\text { Audio } \\
\text { Visual }\end{array}$ & V & 73,24 & 66,88 & 30,21 & 0,21 & Efek kecil \\
\hline AR-05 & $\begin{array}{l}\text { Masruro, } \\
2018\end{array}$ & $\begin{array}{l}\text { Non Tema } \\
\text { (IPS) }\end{array}$ & $\begin{array}{l}\text { Cerita } \\
\text { bergam } \\
\text { bar }\end{array}$ & III & 89,03 & 78,71 & 9,91 & 1,04 & $\begin{array}{l}\text { Efek } \\
\text { tinggi }\end{array}$ \\
\hline AR-06 & $\begin{array}{l}\text { Subhanadri, } \\
2018\end{array}$ & $\begin{array}{l}\text { Tema } \\
\text { (tidak di } \\
\text { jelaskan) }\end{array}$ & $\begin{array}{l}\text { Non } \\
\text { Media }\end{array}$ & I & 70,73 & 58,56 & 3,17 & 3,84 & $\begin{array}{l}\text { Pengaruh } \\
\text { yang tinggi }\end{array}$ \\
\hline AR-07 & $\begin{array}{l}\text { Mulyani, } \\
2019\end{array}$ & $\begin{array}{l}\text { Non Tema } \\
(\mathrm{MM})\end{array}$ & $\begin{array}{l}\text { Papan } \\
\text { Berpak } \\
\text { u }\end{array}$ & $\mathrm{V}$ & 84,29 & 58,67 & 2,34 & 10,95 & $\begin{array}{l}\text { Pengaruh } \\
\text { yang tinggi }\end{array}$ \\
\hline AR-08 & $\begin{array}{l}\text { Agustina, } \\
2020\end{array}$ & $\begin{array}{l}\text { Sehat itu } \\
\text { penting }\end{array}$ & $\begin{array}{l}\text { Audio } \\
\text { Visual }\end{array}$ & V & 75,53 & 70,63 & 7,6 & 0,64 & $\begin{array}{l}\text { Efek } \\
\text { sedang }\end{array}$ \\
\hline AR-09 & $\begin{array}{l}\text { Hargiyantor } \\
\mathrm{o}, 2014\end{array}$ & $\begin{array}{l}\text { Non Tema } \\
\text { (IPA) }\end{array}$ & $\begin{array}{l}\text { Media } \\
\text { Gamba } \\
r\end{array}$ & V & 48,15 & 51,07 & 11,11 & $-0,26$ & $\begin{array}{l}\text { Efek yang } \\
\text { dapat } \\
\text { diabaikan }\end{array}$ \\
\hline AR-10 & $\begin{array}{l}\text { Chasanah, } \\
2017\end{array}$ & Ekosistem & $\begin{array}{l}\text { Genius } \\
\text { Turtle } \\
\text { Card }\end{array}$ & $\mathrm{V}$ & 83,23 & 77,27 & 5.50 & 1,08 & $\begin{array}{l}\text { Efek } \\
\text { tinggi }\end{array}$ \\
\hline
\end{tabular}


Kharisma. Meta Analisis : Pendekatan Saintifik

Berdasarkan table tabulasi di atas diperoleh hasil effect size untuk masing-masing kaitan di bawah ini :

1. Besar pengaruh pendekatan pendekatan saintifik terhadap hasil belajar pada tingkat kelas SD

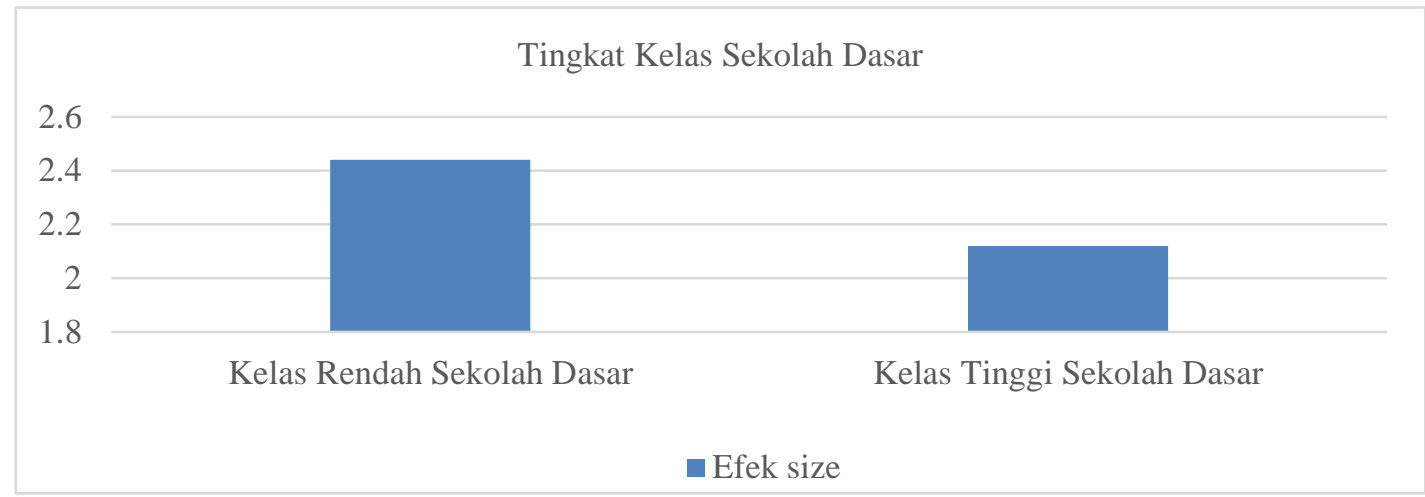

\section{Gambar 1. Pengaruh Pendekatan Saintifik terhadap Hasil Belajar Siswa pada Tingkat Kelas SD \\ Sumber : Dokumen Peneliti}

Hasil meta-analisis pengaruh pendekatan saintifik terhadap pembelajaran tematik pada kelas sekolah dasar, diperoleh bahwa pendekatan saintifik memberikan pengaruh yang tinggi terhadap siswa sekolah dasar kelas rendah. Sedangkan pada jenjang kelas tinggi, pendekatan saintifik memberikan pengaruh pengaruh yang tinggi terhadap hasil belajar dengan nilai Effect Size lebih rendah. Hal ini menunjukkan bahwa pengaruh pendekatan saintifik lebih efektif jika dipergunakan pada pembelajaran di kelas rendah Sekolah Dasar.

2. Besar pengaruh pendekatan saintifik terhadap hasil belajar pada tema pembelajaran

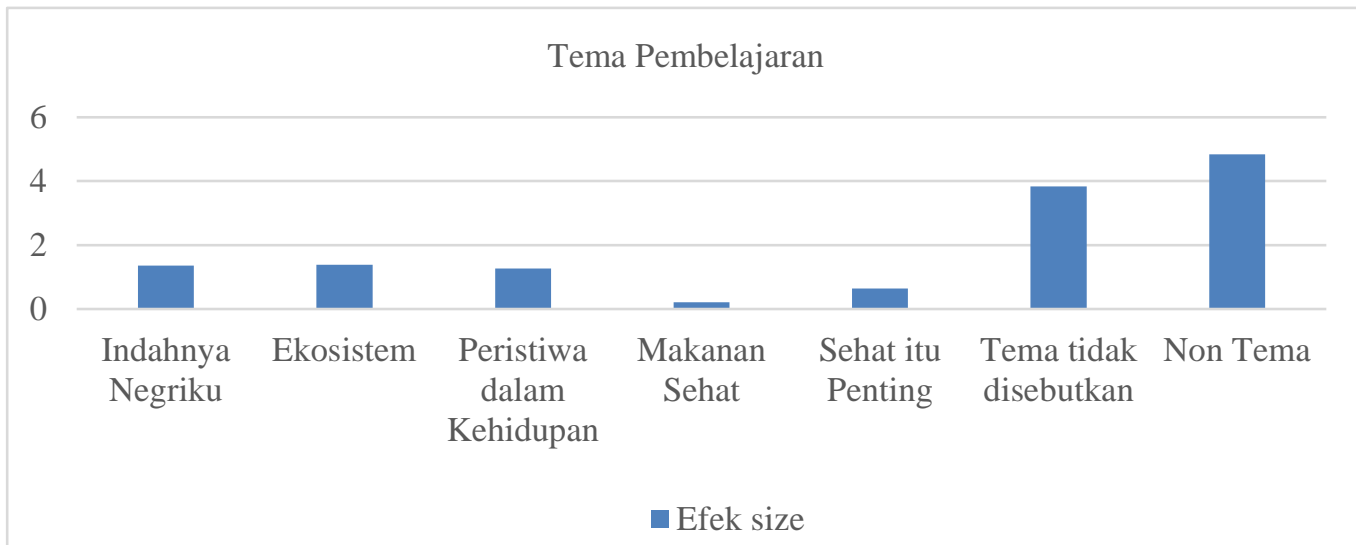

Gambar 2. Pengaruh Pendekatan Saintifik terhadap Hasil Belajar Siswa pada Tema Pembelajaran di SD

Sumber : Dokumen Peneliti 


\section{Kharisma. Meta Analisis : Pendekatan Saintifik}

Berdasarkan tema pembelajaran, hasil meta-analisis menunjukkan bahwa pengaruh yang tinggi pembelajaran yang menggunakan pendekatan saintifik terhadap hasil belajar siswa pada pembelajaran non tema. Sedangkan pada pembelajaran tema makanan sehat memberikan efek kecil pada pembelajaran.

3. Besar pengaruh pendekatan saintifik terhadap hasil belajar pada media yang digunakan

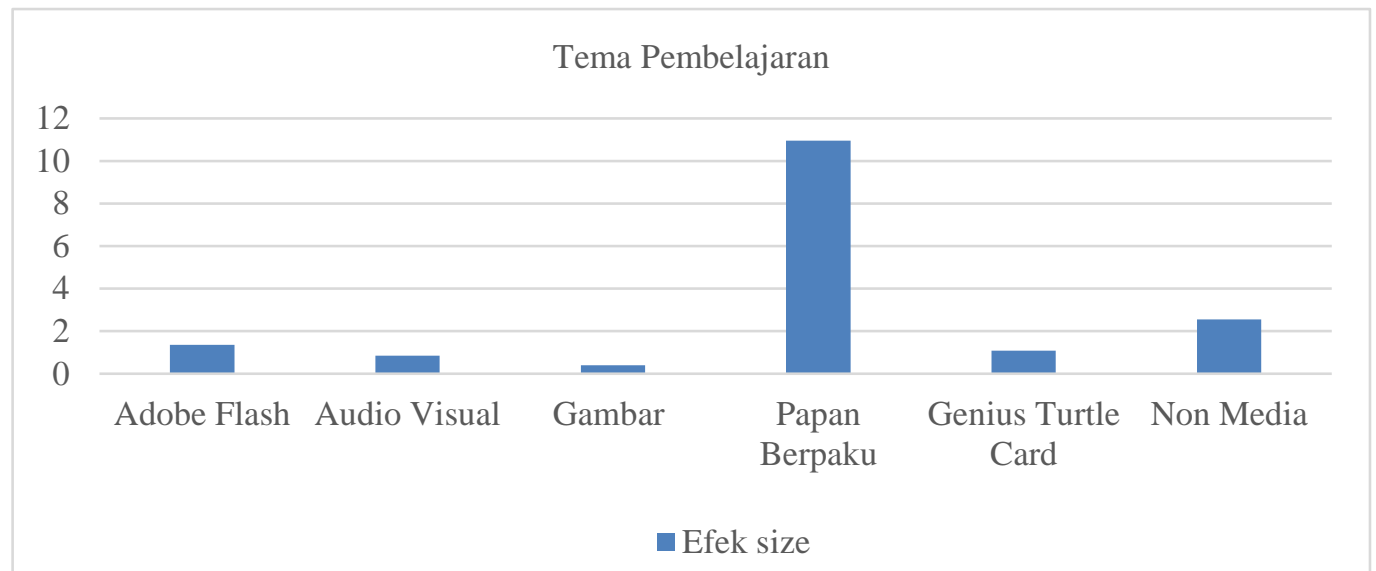

\section{Gambar 3. Pengaruh Pendekatan Saintifik terhadap Hasil Belajar Siswa pada Media Pembelajaran Sumber : Dokumen Peneliti}

Hasil meta-analisis pengaruh pendekatan saintifik terhadap hasil belajar pada media yang digunakan, diperoleh bahwa pengaruh yang tertinggi pada media Papan Berpaku. Sedangkan media yang mempunyai efek paling kecil pada pembelajaran yang menggunakan pendekatan saintifik terhadap media gambar.

\section{PEMBAHASAN}

Secara kesemuanya, pendekatan saintifik hampir membarikan efek yang positif terhadap hasil belajar siswa. Dapat di lihat dari subjek perbedaan tingkat kelas Sekolah Dasar nya yang mana pendekatan saintifik digunakan, penemuan yang diperoleh menunjukkan bahwa penerapan pendekatan saintifik berpengaruh tinggi pada siswa di kelas rendah sekolah dasar disbanding dengan siswa di kelas tinggi. Hal ini berarti

Dari subjek tema pembelajaran, pendekatan saintifik memberikan pengaruh yang tertinggi pada pembelajaran per mata pelajaran atau non tema, akan tetapi untuk pembelajaran menggunakan tema yang memberikan efek yang sangat tinggi pada tema 
Kharisma. Meta Analisis : Pendekatan Saintifik

ekosistem. Dan untuk pembelajaran menggunakan pendekatan saintifik yang memberi efek kecil terhadap hasil belajar siswa adalah pada tema makanan sehat.

Srdangkan, dari aspek penilaian media dalam pembelajaran ternyata pembelajaran menggunakan pendekatan saintifik pada penggunaan media papan paku berpengaruh yang tinggi terhadap hasil belajar siswa dari pada media yang lainnya.

\section{SIMPULAN}

Dari hasil meta-analisis yang telah dilakukan pada penelitian ini dapat disimpulkan bahwa penggunaan pendekatan saintifik berpengaruh tinggi terhadap hasil belajar siswa. Jika pendekatan saintifik digunakan pada siswa kelas rendah Sekolah Dasar berpengaruh sedikit lebih tinggi daripada siswa kelas tinggi, sedangkan dari subjek tama pembelajaaran pendekatan saintifik non tema berpengaruh tinggi terhadap hasil belajar siswa, sedangkan pembelajaran saintifik dengan menggunakan tema yang mempunyai efek yang tinggi terhadap hasil belajar siswa adalah pada tema ekosistem. Dan untuk subjek media pembelajaraan yang digunakan yang berpengaruh tinggi terhadap hasil belajar adalah menggunakan media papan paku.

\section{DAFTAR RUJUKAN}

Asror, A. H. (2016, February). META-ANALISIS: PBL. In PRISMA, Prosiding Seminar Nasional Matematika (pp. 508-513).

Dimyati dan Mudjiono. (2006). Belajar dan Pembelajaran. Jakarta: Rineka Cipta.

Ernawati, I. M., \& Fitriyah, C. Z. Pengaruh Penerapan Pendekatan Saintifik Berbantu Media Audio Visual Terhadap Hasil Belajar Siswa Kelas V Tema Ekosistem Di SDN Ajung 03 Jember. Sumber (Masyhud, 2014: 153), 100(O1), O2.

Fogarty, Robin. (2009). How to Integrate the Curricula (Third Edition). United. States of America: Library of Congress Catalonging in Publication Data.

Glass, G.V., McGaw B., \& Smith, M.L. 1981. Meta-Analysis in Social Research. Sage Publications. London: Sage Publications.

Hargiyantoro, D., Rosnita, R., \& Kartono, K. (2015). Pengaruh Pendekatan Saintifik terhadap Hasil Belajar IPA Siswa Kelas V Sdn 16 Pontianak Selatan (Doctoral dissertation, Tanjungpura University).

Masruro, L., \& Gunansyah, G. (2018). Penggunaan Media Cerita Bergambar Terhadap Hasil Belajar Siswa pada Materi IPS Kelas III SD YPI Darussalam CermeGresik. Jurnal Penelitian Pendidikan Guru Sekolah Dasar, 6(2). 
Kharisma. Meta Analisis : Pendekatan Saintifik

Mulyani, T. (2019). PENGARUH MEDIA PAPAN BERPAKU DALAM MENINGKATKAN HASIL BELAJAR MATEMATIKA SISWA DI KELAS V SDN 118 PEMATANG RIDING KABUPATAN SELUMA (Doctoral dissertation, IAIN BENGKULU).

Pangestika, R. R. (2018). Pengembangan Multimedia Interaktif Adobe FlashÂ円 pada Pembelajaran Tematik Integratif Berbasis Scientific Approach Subtema Keindahan Alam Negeriku. KEGURU" Jurnal Ilmu Pendidikan Dasar", 2(1), 93106.

Permendikbud No. 65 Tahun 2013 Tentang Standar Proses Pendidikan Dasar dan Menengah.

Permendikbud. (2014). Peraturan Menteri Pendidikan dan Kebudayaan Republik Indonesia Nomor 57 Tahun 2014 Tentang Kurikulum 2013 Sekolah Dasar/Madrasah Ibtidaiyah

RADIATUL MAULIDA, A. (2020). PENGARUH PENGGUNAAN MEDIA AUDIO VISUAL TERHADAP HASIL BELAJAR TEMA 3 SUBTEMA 1 BAGAIMANA TUBUH MENGOLAH MAKANAN SISWA KELAS V SDN 6 PALANGKA DI PALANGKA RAYA TAHUN AJARAN 2019/2020 (Doctoral dissertation, Universitas Palangka Raya).

Rahmawati, M. C., \& Dewi, N. D. L. (2019). Kombinasi pendekatan saintifik dan lingkungan serta pengaruhnya terhadap hasil belajar IPA siswa SD. JIPVA (Jurnal Pendidikan IPA Veteran), 3(1), 28-37.

SUBHANADRI, S. (2018). Pengaruh Pendekatan Scientific Terhadap Hasil Belajar Tematik Peserta Didik. Jurnal Muara Pendidikan, 3(1), 68-77.

Danim, Sudarwan. 2013. Menjadi Peneliti Kualitatif. CV Pustaka Setia: Bandung

Uswatun Chasanah, L. (2017). PENGARUH PENGGUNAAN MEDIA GENIIUS TURTLE CARD TERHADAP HASIL BELAJAR SISWA KELAS V TEMA EKOSISTEM SDN WIYUNG 1/453 SURABAY. Jurnal Penelitian Pendidikan Guru Sekolah Dasar, 5(3).

Agustia, F., \& Simpun, M. P. (2019). PENGARUH PENGGUNAAN MEDIA AUDIO VISUAL TERHADAP HASIL BELAJAR TEMA 4 SUBTEMA 2 GANGGUAN KESEHATAN PADA ORGAN PEREDARAN DARAH SISWA KELAS V SDN-6 PALANGKA DI PALANGKA RAYA TAHUN AJARAN 2019/2020 (Doctoral dissertation, Universitas Palangka Raya). 